\title{
The Urethral Sphincter Muscle in the Male
}

\author{
THOMAS M. OELRICH \\ Department of Anatomy, 3736 Medical Science II, The University of Michigan, \\ Ann Arbor MI 48109
}

\begin{abstract}
The male urethral sphincter is a striated muscle in contact with the urethra from the base of the bladder to the perineal membrane. The individual muscle fibers are 25 to $30 \%$ smaller than fibers of associated muscles and are embedded in connective tissue which obscures the visibility of the whole muscle.

The muscle primordium is laid down around the urethra prior to the development of the prostate. Subsequently, the prostate develops as a diverticulum of the urethra and grows into the developing sphincter, thinning the overlying musculature. With the onset of puberty, accelerated growth of the prostate displaces the sphincter, with atrophy of the overlying muscle, resulting in what may appear to be isolated segments of the sphincter muscle distributed around the prostate. The prostate overgrows the anterior portion of the urethra and the associated sphincter muscle.

There is no distinct superior fascia of the so-called urogenital diaphragm separating the sphincter muscle from the prostate. The fascia of the sphincter muscle is inseparable from the prostatic sheath, is oriented vertically, and passes through the urogenital hiatus to unite with the fascia of the pudendal canals at the isochiopubic rami. Thus, the sphincter muscle is a component of a bladderurethra-prostate-sphincter unit which lies within the pelvis, in the urogenital hiatus, and rests upon the perineal membrane. The concept of a urogenital diaphragm is not borne out by this study.
\end{abstract}

The urethral sphincter muscle (M. sphincter urethrae) in the male is one of the least understood muscles in the human body. Its inaccessibility, its great infiltration by connective tissue and vasculature, along with the relatively small size of the muscle fibers create difficulties in defining it by gross dissection, for both anatomist and student.

The sphincter is a striated muscle molded by adjacent structures. During fetal development, the sphincter is affected by the attachment of the urogenital septum and the developing prostate. Because this muscle is associated with secondary sexual organs (prostate, bulbourethral glands, ejaculatory ducts), it undergoes additional modifications which occur at puberty. In the adult, the infiltration of connective tissue, invasion by the prostatic vascular plexuses, and subsequent degenerative changes in the prostate continue to modify the sphincter musculature.

Henle (1873) was probably the first to provide a description of the urethral sphincter muscle, although others had identified it as a striated sphincter. Henle recognized striated fibers "of the prostate" which lie between the prostate and the base of the bladder (M. sphincter vesicae externus) and, somewhat more caudally, striated fibers which unite the anterior borders of the prostate (M. compressor prostatae). Henle described two aponeuroses, an upper and a lower, which contain the $\mathbf{M}$. transversus perinei profundus (a urogenital diaphragm). The latter muscle contains the bulbourethral gland and the membranous urethra. He indicated that the superior aponeurosis separates this muscle from the prostate and that there may be continuity with the muscles of the prostate. Holl (1897) divided the M. transversus perinei profundus into $M$. sphincter urethrae membranaceae, M. compressor glandulae Cowperi, and an M. transversus perinei profundus. Holl also indicated that there is continuity with the M. sphincter urethrae prostaticae. The concept of a urogenital diaphragm dates from these de-

Received June 1, 1979; accepted February 28, 1980. 
scriptions. Kalischer ('00) described characteristics of the sphincter musculature in both the child and adult. Gil Vernet ('53) documented many details of the sphincter, while Hayek ('60) described details of the muscle fibers and, later ('62), discussed the functional aspects. Haines ('69) described the muscle in a fourand a five-year-old child. Regardless of the available literature, none of the American textbooks of anatomy present an accurate description of the sphincter muscle, while European texts such as Poirier and Charpy ('01), Testut ('49), and Braus ('60), for example, have more accurate descriptions.

Some American authors have examined the structure of the sphincter mechanism to determine why striated muscle is found in the prostate. Wesson ('20) accurately portrayed it in his illustrations. Rolnick and Falk ('49) and Hutch and Rambo ('67) presented some muscular details, but were concerned with specific problems of urinary continence and function and were limited by the concept of a urogenital diaphragm. Manley ('66) reidentified the proximal fibers of the sphincter at the base of the bladder (M. Sphincter vesicae externus of Henle).

Though there are descriptions of the sphincter urethrae muscle in the literature, authors have failed to examine the developing sphincter and the effect of developing secondary sexual organs at puberty on the sphincter. Thus, some authors have described the muscle as consisting of separate parts and have ascribed specific functions to each part, rather than recognizing the continuity of the whole and understanding that these apparent parts are the result of the prostate growing into the muscle.

The predisposition toward the concept of a urogenital diaphragm has perpetuated errors, both conceptual and descriptive, in texts and reference works. Delbet (Poirier and Charpy's Triaté d' Anatomie humaine, '01) recognized that there is no specific deep layer of the urogenital diaphragm. Smith ('08) indicated that there is no deep perineal pouch. Derry ('07) doubted the existence of a superior fascia of the urogenital diaphragm. Courney ('50) recognized the incorrectness of textbook descriptions of the urogenital diaphragm, while Haines ('69) reiterated that there can be no superior fascia.

It is the purpose of this paper to describe the human sphincter urethrae muscle in its various developmental processes and its varying structural states (early development, pre- puberal, post-puberal) to clarify its structure and bring unity to its "parts." With clarification of the sphincter muscle, it will become apparent that the urogenital diaphragm is a concept that can no longer be supported.

\section{MATERIALS AND METHODS}

Initially, dissections of the sphincter muscle were attempted under low magnification. This effort was fraught with difficulty and error due to the infiltration of connective tissue and the vasculature of the prostatic venous plexus found in the typical laboratory cadaver of 50 or more years. It was thus necessary to section the region serially and stain with trichrome stain to identify the musculature.

Blocks of tissue extending from the base of the bladder to the skin of the perineum and laterally as far as the ischiopubic rami were obtained from 15 specimens ranging in age from term to 70 years. Frontal and sagittal sections were made from the halves of the same specimen; in others, alternative frontal and cross-sections were made, Complete serial sections were cut at 25-50 micrometers and stained with Masson's triple stain. The pelvis from 21 fetuses, ranging from 40-mm-C.R.L. to term, were sectioned serially and examined.

After establishing a more accurate concept of the sphincter muscle from the sectioned material, 50 specimens ranging in age from term to 25 years were dissected under lowpower magnification. Gross dissections were practical at these ages and confirmed, in three dimensions, the arrangement of the muscle and fascia seen in sections.

\section{RESULTS}

\section{The muscle fiber}

The structure of the muscle fibers of the urethral sphincter is sufficiently distinctive to be considered separately. The fibers are spaced regularly and each is surrounded by a quantity of connective tissue which may be greater in thickness than the diameter of the muscle fiber (Figs. 1, 2). The quantity of connective tissue is proportional to age and development of the individual and is proportionately greater than that in associated muscles such as the levator ani, obturator internus, ischiocavernosus, or bulbospongiosus. In the child and adolescent (Fig. 3), this relationship is maintained.

There is a lack of fasciculation throughout the muscle, so that conventional terms cannot be applied to the connective tissue of the 
sphincter mechanism. This characteristic also varies with development and age. In the fetus, there is a clumping of muscle fibers that resembles fasciculation (Fig. 15). In the adult, comparison with adjacent pelvic and perineal musculature (Fig. 5) readily differentiates conventional fasciculation.

There is a distinctive arrangement of connective tissue. Septa extend from the peripheral investing fascia through the muscle to the urethra (Fig. 4). These septa, though thick peripherally, become thin as they reach the urethra and give the appearance of stratification to the muscle. This characteristic is variable and is readily seen in adults, in which the connective tissue mass is increased.

The diameter of the muscle fibers in the sphincter is relatively small (Hayek, '60). Comparison of the diameters of the muscle fibers of the sphincter urethrae (Fig. 7) of one individual with the diameters of those in associated musculature (Fig. 6) (levator ani, bulbospongious, ischiocavernosus, obturator internus) revealed that the sphincter urethrae fibers were 25 to $30 \%$ smaller. Absolute measurement cannot be given because of the different ages of specimens and individual variation.

In older adults, the ventral and lateral portions of the sphincter are invaded by the extensive prostatic vascular plexuses (Fig. 2). In dissection this provides an appearance similar to cavernous tissue. Due to this vascular invasion, the integrity of the muscle as a distinctive structure may be lost, which, perhaps, accounts for errors in textbook descriptions.

\section{The urethral sphincter muscle}

\section{Early development}

The structure of the sphincter musculature can best be understood by examining the developing fetus. Early fetal stages show the arrangement of mesodermal condensations differentiating to smooth and striated muscle.

In the 60-mm-C.R. fetus one can distinguish between the multinucleated cells which will become striated muscle and the cells which will become smooth muscle, in the pelvic diaphragm and other associated musculature; however, the mesenchyme surrounding the urethra does not show these distinctions, altough the basic pattern of the sphincter mechanism is evident. Above the primordium of the bulbospongiosus muscle (Fig. 8), there is a circular arrangement of the primordium of the sphincter urethrae. It is thick anteriorly and becomes thin as it encircles the urethra to the dorsal side. At the mid-dorsal line there is evidence of a septum. Ascending along the urethra toward the base of the bladder, the posterior wall of the urethra becomes thickened (Fig. 9). This is the junction of the fused paramesonephric ducts and mesonephric ducts with the urethra, which limits the cephalic extent of the primordial sphincter on the dorsal side. At the union of the bladder and urethra (Fig. 10), the sphincter primordium is seen only on the ventral and lateral side of the urethra.

Simply described, the primordial urethral sphincter resembles a signet ring-like condensation of mesenchyme surrounding the developing urethra. It extends along the urethra, ventrally, from the primordial corpus spongiousum to the base of the bladder and, dorsally, from the corpus spongiousum to the junction of the urogenital septum with the urethra. The superior border of the sphincter primordium extends diagonally between its anterior and posterior cephalic extremities. At this stage of development, the attachment of the urogenital septum determines the arrangement of this primordial sphincter. No prostate or prostatic buds are evident. In fetal stages prior to development of the prostate, the adult terms, prostatic and membranous urethra, cannot be applied. The term pre-penile urethra or urethra will be used in identifying these segments of urethra.

In the 94-mm-C.R. fetus (Figs. 11, 12), multinucleated cells and the extent of the sphincter primordium are evident. Near the base of the bladder (Fig. 11) and surrounding the attachment of the urogenital septum (Fig. 12), the urethral wall begins to thicken and the initial prostatic budding of the mucosa occurs. This thickening grows within the sphincter primordium, thus thinning the surrounding mesenchyme. The doral portion of the gland, above the fused mesonephric ducts, is completely uncovered by sphincter primordium, while below the mesonephric ducts, there is still no evidence of sphincter fibers behind the urethra (Fig. 12).

In the 115-mm-C.R. fetus (Fig. 13), the sphincter primordium is beginning to show striations of the mesenchyme. Dorsally, the sphincter primordium protrudes to contact the wall of the rectum, where there appears to be an interruption of the longitudinal smooth muscle of the rectum. Here, smooth muscle fibers will become the rectourethralis muscle 
(Fig. 13). The initial diverticula of the bulbourethral glands are growing into its inferior portion (Figs. 13, 14).

In a frontal section of the 115 -mm-C.R. fetus (Fig. 14), the developing sphincter surrounds the urethra, extending from the perineal membrane to the base of the bladder. Lateral to the mid-length of the sphincter is the pelvic diaphragm.

In the 130-mm-C.R. fetus, striations appear on the muscle fibers. The sphincter completely surrounds the urethra and its fibers have developed across the mid-line, dorsal to the urethra (Fig. 15). Development of the prostate is occurring in the "posterior lobe" or that portion below the ejaculatory ducts, and concurrently, the urethra is beginning to develop a distinct curve (Fig. 15). The caudal extent of the sphincter mechanism now lies just beneath the arcuate pubic ligament and adjacent to the corpus spongiosum.

The 245-mm-C.R. fetus (Figs. 16, 17) shows complete differentiation between striated and smooth muscle, and fascial planes within the pelvis can be distinguished. The striated musculature is continuous with and inseparable from the smooth urethral musculature (Fig. 16). The thickness of the sphincter musculature has become greater than that of the smooth muscle wall of the urethra. No definitive fascial planes separate the two layers. The areas of musculature are fairly sharply defined, with interdigitation of smooth and striated fibers occurring in the planes of contact. (Note this in the adult, Fig. 1).

In a sagittal plane (Fig. 17), the sphincter musculature is seen along the entire anterior wall of the pre-penile urethra, while along the posterior wall, below the developing prostate, it covers only about $60 \%$ of the anterior length. As the muscle sweeps dorsally around the urethra, its upper border lies in a groove between the bladder and prostate (Fig. 16), while more caudal fibers overlie the lateral surface of the prostate.

It is apparent that the sphincter urethrae is a component of a vertical unit consisting of bladder, urethra, prostate, and sphincter, and that this unit lies dorsal to the pubic symphysis and between the two halves of the pelvic diaphragm, residing in the urogenital hiatus above, within, and below the level of the hiatus (Fig. 16). Though modifications of this arrangement occur throughout subsequent growth, the basic pattern, as presented in this stage of development, does not change. The pattern of the structure of the urethral sphincter having been established, few changes other than growth occur in the fetus through term.

\section{Term}

The fetus at term is the first stage in which productive gross dissection can be done. With low magnification, fascial planes, muscle, and glands are readily traceable. The urethral sphincter extends throughout the length of the pre-penile urethra (Fig. 25). The proximal portion of the sphincter lies at the base of the bladder and is horseshoe-shaped. In the more central portion of the sphincter, the fibers cover the lateral surface of the prostate and extend to its posterolateral border (Fig. 25). Caudal to the prostate, the fibers are sphincteric and completely encircle the urethra (Fig. 25). It should be noted that the sphincter is narrowest here, since no prostate is present, and it is this portion of the sphincter which lies in the urogenital hiatus of the pelvic diaphragm. The portion of the sphincter below the pelvic diaphragm rests on the perineal membrane and expands into a triangular wedge which fills the area between the two ischiopubic rami (Fig. 25). That portion behind the urethra expands, corresponding to the development of the bulbourethral glands. Being sphincteric, the muscle does not attach to the ischiopubic rami. Removal of the sphincter muscle shows the bladder, prostate, and urethra (Fig. 26). The prostate is hemispheric, lies posterolateral to the urethra, and occupies one third of the length of the prepenile urethra.

\section{Four years}

The structural arrangement of the urethral sphincter muscle, during the post-natal years prior to puberty is the most important in understanding the sphincter, since within this period the muscle reaches its peak of development, prior to the puberal growth of the prostate and the resulting destruction of much of the sphincter muscle (Compare Figs. 27 and 32 ). It is in this period that gross dissection is the most productive. The rates of growth of the prostate and sphincter appear to be comparable.

In the four-year-old, the bladder, prostate, urethra, and urethral sphincter constitute a tapering cylindrical unit in which the identity and shape of the individual components are obscure (Fig. 27). Here the uninterrupted continuity of the entire sphincter muscle is visible, extending from the bladder to the perineal 
membrane. The fiber bundles are distinct and converge anteriorly toward the concavity of the urethral curve, giving the entire muscle a fan-like appearance (Fig. 27). Proximally, the urethral sphincter is $2-3 \mathrm{ml}$ thick, while the distal expanded mass surrounding the membranous urethra is twice as thick. The dorsal part of the prostate above the ejaculatory ducts is uncovered by sphincter fibers, as in developing stages. Below the ejaculatory ducts the sphincter muscle is thinned, showing the effects of the growth pressure of the posterior lobe (Figs. 27, 28). The fibers surrounding the membranous urethra are distinctly circular (Fig. 28). Some fibers at the periphery of this mass radiate toward the ischiopubic rami both anteriorly and posteriorly, although none attach to bone.

With removal of the sphincter muscle (Fig. 29 ), it is apparent that growth has occurred in the median lobe of the prostate, extending the gland upward, dorsal to the vesicourethral junction (Compare Figs. 26 and 29). The gland has lost its hemispheric shape and has become prismatic, as growth of the lateral lobes has occurred in a posterolateral direction (Fig. 29).

Dorsal to the distal sphincter fibers is the deep transverse muscle of the perineum (Fig. 28 ). Its fibers arise from the fascia of the pudendal canal and interdigitate with the urethral sphincter, the external anal sphincter, and the rectourethralis smooth muscle in the mid-line.

\section{Puberty}

Puberty occurs at varying ages and rates. There is no intent here to imply specific agerelated occurrences.

At age 12 (Fig. 23), the prostate has grown to incorporate nearly $50 \%$ of the pre-penile urethra (Compare Figs. 23 and 29). Growth occurs almost exclusively in the area of the posterior and lateral lobes. The urethral sphincter increases in size comparable to the growth of the individual, although the growth of the prostate is proportionately greater.

Enlargement of the lateral lobes of the prostate has thinned or caused pressure atrophy of that portion of the sphincter which had overlain the lateral lobes.

In early stages of development, the bladderurethral junction is located near the superior border of the pubic symphysis (Figs. 15, 17), and the complete pre-penile urethra is located dorsal to the pubic symphysis. With enlargement of all dimensions of the pelvis and change from the vertical to an oblique orien- tation of the pubic symphysis at puberty, the bladder-prostate-urethral junction descends within the pelvis so that it comes to lie at the level of the distal third of the pubic symphysis.

In the 14-year-old (Fig. 24), the prostate has increased in size throughout, incorporated more than $50 \%$ of the pre-penile urethra, and is spherical in appearance. As the lateral lobes increase in size, they bulge ventrally (Fig. 24). This is in contrast to the distinct posterolateral direction of growth at earlier ages. The forward growth of the lateral lobes has continued the process of pressure atrophy of the sphincter muscle, so that few grossly dissectible fibers are seen on the lateral lobes of the prostate. The grooving and excavation of the prostate (Fig. 24.) clearly show the disposition of the urethral sphincter as it contacts the anterior part of the prostate.

In the late puberal stage of 18 years (Figs. 18-22), near the mid-length of the prostate, the anterior border of the lateral lobes grows forward and begins to overlap the urethra. With this advance the prostate grows into the sphincter and, as a result, the muscle partly overlaps it and is partly contained within it. In a cross-section of the prostate at mid-length (Fig. 19), the overlapped portion of the urethral sphincter may be seen spanning between the anterior portion of the lateral lobes and partly surrounding the urethra. Increased infiltration of connective tissue (prostatic sheath) and vasculature (prostatic venous plexus) into the anterior fibers of the sphincter muscle at this age adds to the difficulty in establishing the structure of this muscle by gross dissection. Near the caudal border of the prostate (Fig. 20), the sphincter surrounds the urethra. In the same section are seen the caudal tips of the lateral lobes of the prostate, posterolateral to the sphincter muscle. This demonstrates the caudal growth of the prostate during this state of enlargement. Caudal to the prostate, the sphincter completely surrounds the urethra (Fig. 21). Below the urogenital hiatus, the sphincter mass enlarges dorsal to the urethra (Fig. 22). These fibers invest the bulbourethral glands and expand toward the pudendal canals.

In sagittal section (Fig. 18), the anterior part of the sphincter lies above the urethra. This is due to the oblique course of the urethra through the prostate and to the curve of the urethra. Anterior to the sphincter muscle, a distinct dense fascial plane extends vertically toward the bladder. This is the transverse ligament of the perineum. 
Adult

Figures 30 and 31 show the adult prostate with the prostatic sheath and all associated musculature removed. The prostate now encompasses approximately $66 \%$ of the pre-penile urethra. There is a more spherical contour to the prostate as a result of the forward growth of the lateral lobes.

Sphincter muscle fibers persist in areas of the urethra from the base of the bladder to the perineal membrane (Fig. 32). Few changes other than growth in size occur between late puberty and the adult, except in that part of the muscle associated with the forward-moving lateral lobes of the prostate. This part of the muscle undergoes reduction according to the degree of growth of these lobes and may vary considerably among individuals.

In the adult sphincter, the most proximal fibers persist as a bundle lying between the base of the bladder and the proximal border of the prostate (Fig. 32). These fibers form a horseshoe-like arrangement, the free end of which intermingles with the smooth muscle fibers of the bladder. The remainder of the bundle passes obliquely downward and forward to cross the urethra ventrally just inferior to the vesicourethral junction (Henle 1873; Manley '66; Haines '69). The next group of fibers is continuous with the above but lies in the region of the forward-developing lateral lobes of the prostate. The extent to which these cover the prostate varies. Though they may not always be grossly visible, sectioned material almost always shows striated muscle on the lateral surface of the prostatic capsule. Deep fibers of the sphincter muscle lying between the lateral lobes vary in size, depending upon the development of the lobes. If the lobes approximate each other at the mid-line, the muscle may be represented only by dense fibrous tissue; however, if the lobes are widely separated (Fig. 31), the sphincter muscle fills the interval, and fibers appear to attach to the capsule (Fig. 19). Deep to these is a more distinct group of fibers which is truly sphincteric, in contact with the urethra. These are oriented obliquely so that their proximal ends lie in front of the prostatic urethra and their caudal ends lie dorsal to the membranous urethra. By observing the excavations of the prostate surrounding the urethra (Fig. 31 ), it is easy to envision the configuration of the sphincter muscle and how it is entrapped by the over-growth of the lateral lobes of the prostate. Caudal to the prostate, the fibers are circular and form a sphincter of the membranous urethra (Figs. 32, 34). This portion lies in the urogenital hiatus of the pelvic diaphragm. Inferior to the pelvic diaphragm, the sphincter expands to fill the area between the pudendal canals (Fig. 34). Two distinct groups of fibers can be identified: those that lie immediately adjacent to the urethra and are sphincteric, and those that lie at the periphery of the mass and expand laterally and dorsally to encircle the bulbourethral glands (Fig. 22).

In a mid-line section of the bladder-urethraprostate and sphincter, one can readily see the association of the sphincter muscle with the urethra (Fig. 33). The muscle is in contact with the urethra ventrally from the base of the bladder to the perineal membrane, while, dorsally, the muscle extends from the prostate to the perineal membrane.

The sphincter muscle lies within the pelvic cavity, within the urogenital hiatus of the pelvic diaphragm and below the pelvic diaphragm (Fig. 34). It is surrounded by a fascial investment which is continuous with the prostatic sheath, derived from extraperitoneal connective tissue (Fig. 34). As these structures enter the urogenital hiatus, the superior fascia of the pelvic diaphragm (transversalis fascia) unites with the fascial sheath of the sphincter and becomes a common fascia which passes around the medial border of the pelvic diaphragm (pubococcygeus, puborectalis) to continue and join the fascia of the pudendal canal (Fig. 34). Anteriorly, this fascial plane passes, from the bladder, caudally between the puboprostatic ligaments to lie on the anterior (ventral) surface of the urethral sphincter, where it ultimately unites with the anterior border of the perineal membrane as the transverse ligament of the perineum (Fig. 18).

\section{DISCUSSION}

M. sphincter vesicae externus, M. constrictor canalis urogenitalis, M. compressor prostatae, M. sphincter urethrae prostaticae, M. sphincter urethrae membranaceae, M. transversus urethrae, and $M$. compressor glandulae Cowperi are terms which have, from time to time, been applied to the M. sphincter urethrae (PNA), either as a synonym or as designations of what have been considered to be specific parts or regions of the urethral sphincter muscle. It has been demonstrated that the urethral sphincter is derived from a single primordium and that, in early development, 
the resulting sphincter muscle extends without interruption from the bladder to the perineal membrane. The prostate develops from the urethra and grows into the overlying striated sphincter muscle. At the onset of puberty, the developing prostate further invades the sphincter muscle, thinning the overlying parts and causing a reduction or atrophy of some of the muscle, while overlying some of the sphincter and incorporating it within the prostatic perimeter.

In comparison, the urethral sphincter of the adult gorilla resembles, in degree of development, that of the human full-term fetus and child (Oelrich, '78). The prostate in the gorilla is paired, and each gland attaches to its respective urethral sinus lateral to the seminal colliculus. The prostate does not encircle the urethra and, therefore, does not invade or compromise the urethral sphincter.

There is no subdivision of the human urethra sphincter muscle by fascial planes, and no smooth muscle septa have been recognized dividing the muscle into parts (Hayek, '62). While there is regional differentiation, this exists as a result of the growth of the secondary sexual organs. As these organs increase in size, the sphincter muscle is reduced accordingly, therefore sacrificing the effectiveness of the more proximal parts of the muscle.

The concept of a urogenital diaphragm implies that the urethral sphincter is a transverse plane of muscle spanning between the two ischiopubic rami and surrounding the membranous urethra. In this concept, two fascial planes envelop the muscle; one plane, the inferior fascia of the urogenital diaphragm (perineal membrane), lies inferior to the muscle sheet, and the other, the superior fascia of the urogenital diaphragm, is said to be above the sphincter and extend to the urethra, separating the muscle from the prostate. The entire structure is described as lying below or outside the pelvic cavity.

It has been clearly demonstrated in this study that the urethral sphincter is not a horizontal plane, but that it lies within the pelvic cavity and within the urogenital hiatus, and that it extends from the bladder to the perineal membrane. Also, this muscle is associated throughout with the prostate (Fig. 32 ) and not just with the membranous ureth$\mathrm{ra}$. The fascia which surrounds the sphincter muscle and prostate is a vertically oriented tubular sheath and not a pair of transverse planes (Fig. 34).
The bladder, prostate, urethra, and the urethral sphincter muscle constitute a unit of visceral structures. Since the pelvic diaphragm is incomplete ventrally (the urogential hiatus), no direct support for the urogenital viscera is provided by the pelvic diaphragm. These viscera, therefore, lie in the urogenital hiatus and rest upon the perineal membrane (Compare Figs. 14, 16, 34).

\section{ACKNOWLEDGMENTS}

I wish to express appreciation for the art work provided by William Brudon.

This work was supported in part by a grant from the United States Public Health Service-NIH 5R01 GM 09773-02.

\section{IITERATURE CITED}

Braus, H. (1960) Anatomie des Menschen. Springer-Verlag., Berlin.

Courtney, H. (1950) Anatomy of the pelvic diaphragm and anorectal musculature as related to sphincter preservation in anorectal surgery. Am. J. Surg., 79:155-173.

Derry, D. (1907) Pelvic muscles and fasciae. J. Anat., 42:107-111.

Gil Vernet, S. (1953) Patología Urogenital. Tomo II, Vol. I., Biología y patología de la prostata., Edit. Paz Montalvo, Madrid.

Haines, R.W. (1969) The striped compressor of the prostatic urethra. British Journal of Urology., 41:481-493.

Hayek, H. (1960) Das Faserkaliber in den Mm. transversus perinei und Sphincter urethrae. Zeitscrift für Anatomie und Entwicklungsgeschichte., 121:455-458.

Hayek, H. (1962) Zur Anatomie des Sphincter urethrae. Zeitschrift für Anatomie und Entwicklungsgeschichte., 123: $121-125$.

Henle, J. (1873) Handbuch der systematischen Anatomie des Menschen. Bd. II., Eingeweidelehre., Freiderich Vieweg and Sohn, Braunschweig.

Holl, M. (1897) Die Muskeln und Fascien des Beckenausganges. In Handbuch der Anatomie des Menschen., Bardeleben., Gustav Fischer, Jena.

Hutch, J., and O. Rambo (1967) A new theory of the anatomy of the internal urinary sphincter and the physiology of micturition. J. Urol., 97:696-704.

Kalischer, O. (1900) Die Urogenitalmuskulatur des Dammes. Verlag Von S. Karger., Berlin.

Manley, C.B. (1966) The striated muscle of the prostate. J. Urol., 95:234-240.

Oelrich, T.M. (1978) Pelvic and perineal anatomy of the male gorilla: selected observations. Anat. Rox., 191:433-446.

Poirier et Charpy. (1901) Triaté d' Anatomie humaine. Tome V., Masson et Cie, Paris.

Rolnick, H., and H. Falk (1949) An anatomic study of the external urethral sphincter in relation to prostatic surgery. J. Urol., 61:591-603.

Smith, G. (1908) Studies in the anatomy of the pelvis, with special reference to the fasciae and visceral supports. J. Anat., 42:252-270.

Testut, L., et A. Latarjet (1949) Triaté d' Anatomie humaine. Tome V, Gaston Doin \& Cie, Paris.

Wesson, M.B. (1920) Anatomical, embryological and physiological studies of the trigone and neck of the bladder. J. Urol., 4:279-315. 
Abbreviations

B Bladder

BU Bulbourethral gland

BS Bulbospongiosus muscle

CC Corpus cavernosum penis

CS Corpus spongiosum penis

CTS Connective tissue septa

DD Ductus deferens

DTP Deep transverse muscle of the perineum

F Femoral head

I Mium

IC Ischiocavernosus muscle

IP Inferior pubic ramus

MD Fused paramesonephric ducts

OE Obturator externus muscle
OI Obturator internus muscle

PD Pelvic diaphragm

P Pubis

PM Perineal membrane

PR Prostate

$\mathrm{R}$ Rectum

RU Rectourethralis muscle

SU Sphincter urethrae muscle

SV Seminal vesicle

U Urethra

UM Smooth muscle of urethral wall

US Urethral sphincter muscle

TLP Transverse ligament of the perineum

$\rightarrow \leftarrow$ Plane of perineal membrane

Fig. 1. Frontal section through urethral sphincter muscle of a 39-year-old male (urethra on left). $\times 24$.

Fig. 2. Frontal section through urethral sphincter muscle of a 70-year-old male. $\times 24$.

Fig. 3. Frontal section through urethral sphincter muscle of an 18-year-old male (urethra on left). $\times 24$.

Fig. 4. Frontal section through urethral sphincter muscle of a 32-year-old male (urethra on left). $\times 24$.

Fig. 5. Cross section of levator ani muscle showing conventional fasciculation, 28-year-old male. $\times 24$.

Fig. 6. Cross section of levator ani muscle showing size of muscle fiber, 28-year-old male. $\times 100$.

Fig. 7. Crass section of urethral sphincter muscle showing size of muscle fiber, 28-year-old male. $\times 100$.

(Figures 6 and 7 are from the same specimen, the same section at the same magnification.) 

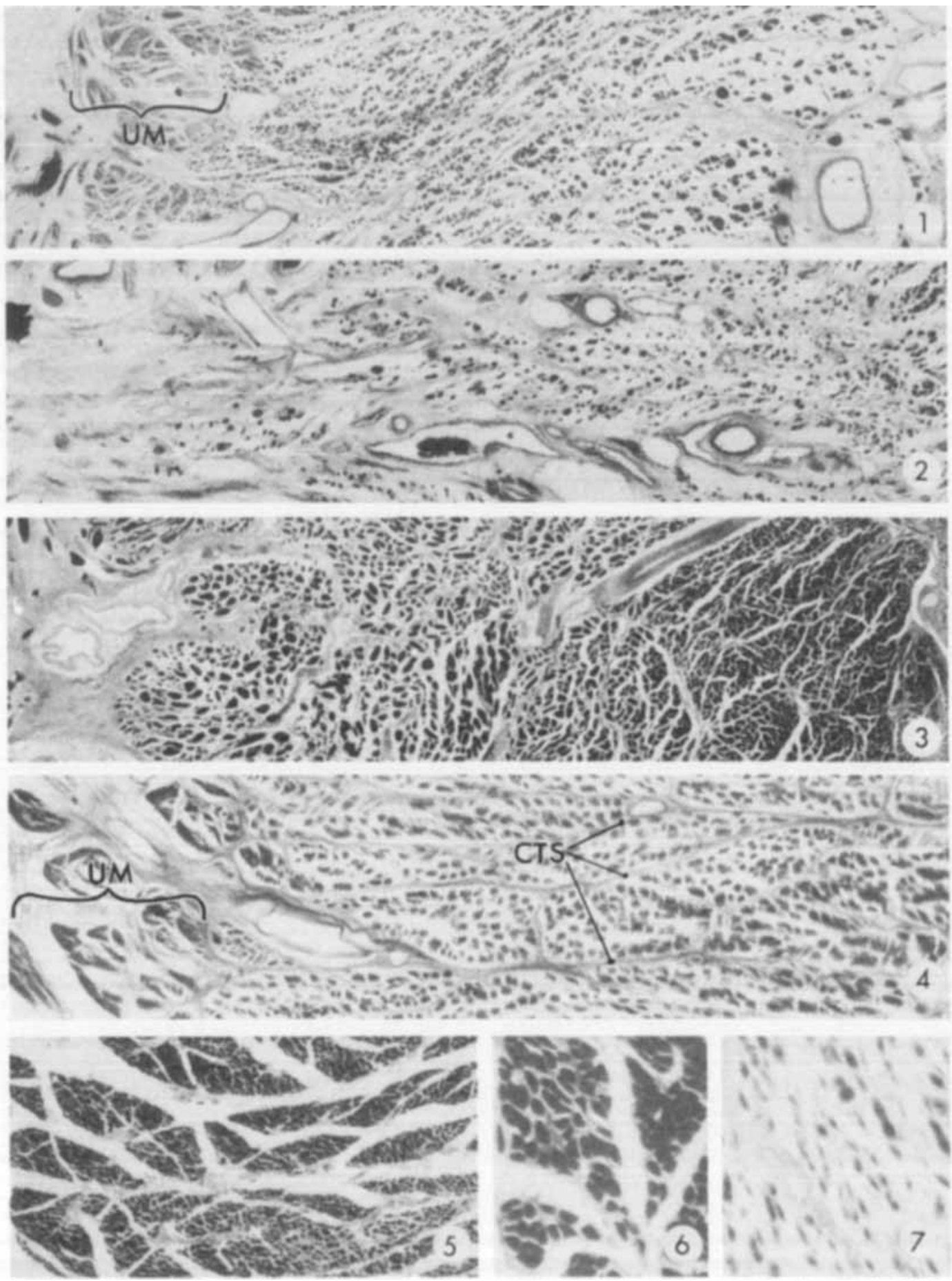
Fig. 8. Cross section of male urethra in a 60-mm-CR fetus, just proximal to corpus spongiosum. Note pelvic diaphragm lateral to urethra. $\times 25$.

Fig. 9. Cross section of male urethra in a $60-\mathrm{mm}-\mathrm{CR}$ fetus at level of primordial seminal colliculus, primondial urethral sphincter ventral and lateral. $\times 25$.

Fig. 10. Cross section of male urethra in a $60-\mathrm{mm}-\mathrm{CR}$ fetus near base of the bladder, primordial urethral sphincter ventral and lateral, fused paramesonephric ducts dorsal to urethra. $\times 25$.

Fig. 11. Sagittal section of a 94-mm-CR male fetus demonstrating development of urethral sphincter and prostate. $\times 10$.

Fig. 12. Median section of a 94-mm-CR male fetus through the lumen of the urethra demonstrating junction of paramesonephric ducts. $\times 10$.

Fig. 13. Sagittal section of a 115-mm-CR male fetus demonstrating development of urethral sphincter, prostate, and rectourethralis muscle. $\times 12$.

Fig. 14. Frontal section of 115-mm-CR male fetus showing developing urethra, sphincter urethrae, and bladder in relation to pelvic diaphragm and urogenital hiatus. $\times 12$. 

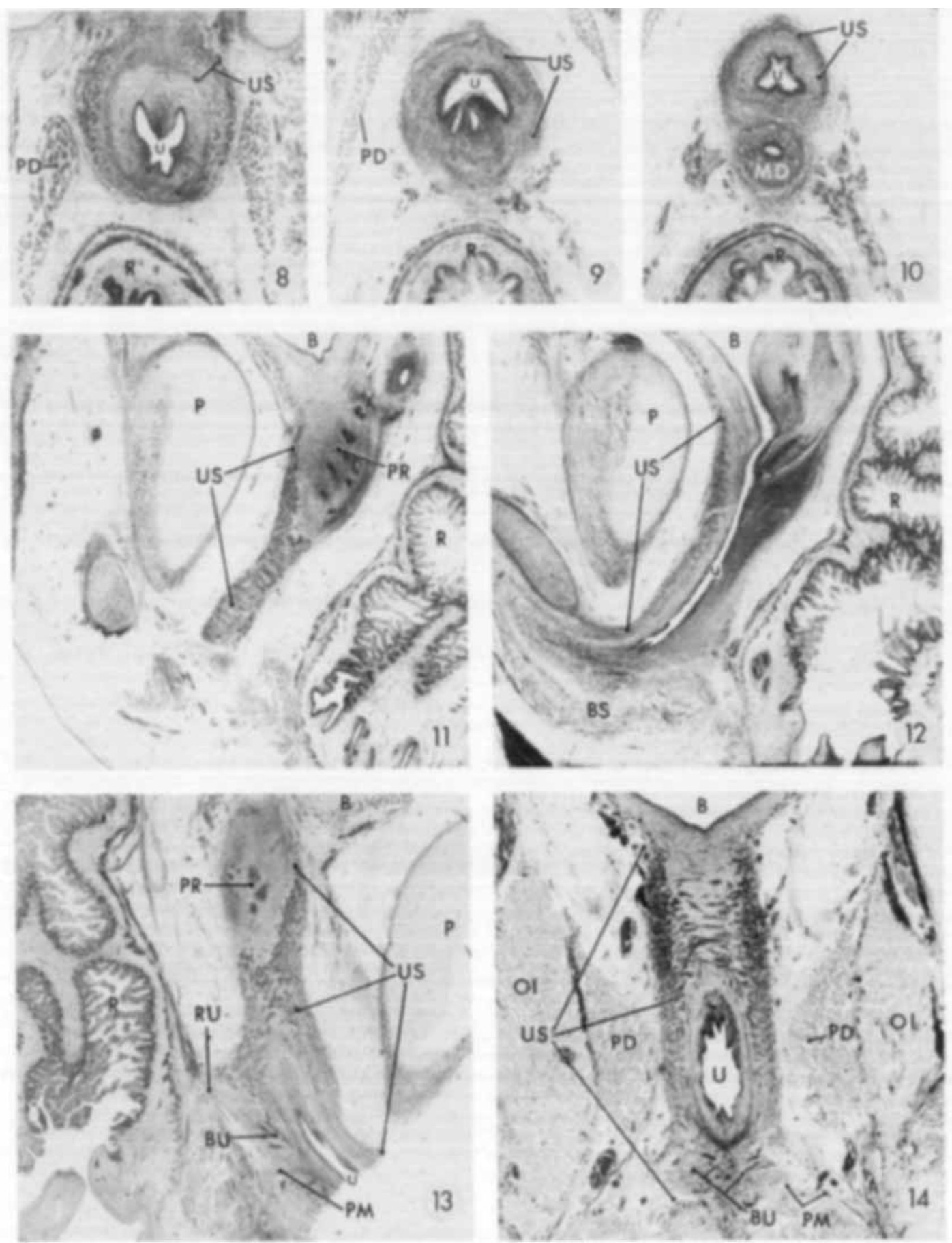
Fig. 15. Sagittal section of a $130-\mathrm{mm}-\mathrm{CR}$ male fetus showing differentiated urethral sphincter completely surrounding the urethra. $\times 10$.

Fig. 16. Frontal section of a $245-\mathrm{mm}$-CR male fetus demonstrating relation of urethra, prostate, perineal membrane, and pelvic and urogenital musculature. $\times 3.75$.

Fig. 17. Sagittal section of a $245-\mathrm{mm}$-CR male fetus showing complete extent of urethral sphincter. Note pubovesical fibers between pubis and urethral sphincter. $\times 3.75$.

Fig. 18. Sagittal section of an 18-year-old male urethra sphincter and perineal structurcs. $\times$ 1.5.

Fig. 19-22. Cross section of left half of urethra and urethral sphincter of an 18-year-old male showing various relations of the urethra sphincter.

Fig. 19. At mid-length of the prostate. $\times 2$.

Fig. 20. Inferior pole of lateral lobes of prostate. $\times 2$.

Fig. 21. Urethra in urogenital hiatus. $\times 2$.

Fig. 22. Urethral sphincter below the pelvic diaphragm and urogenital hiatus. $\times 2$. 

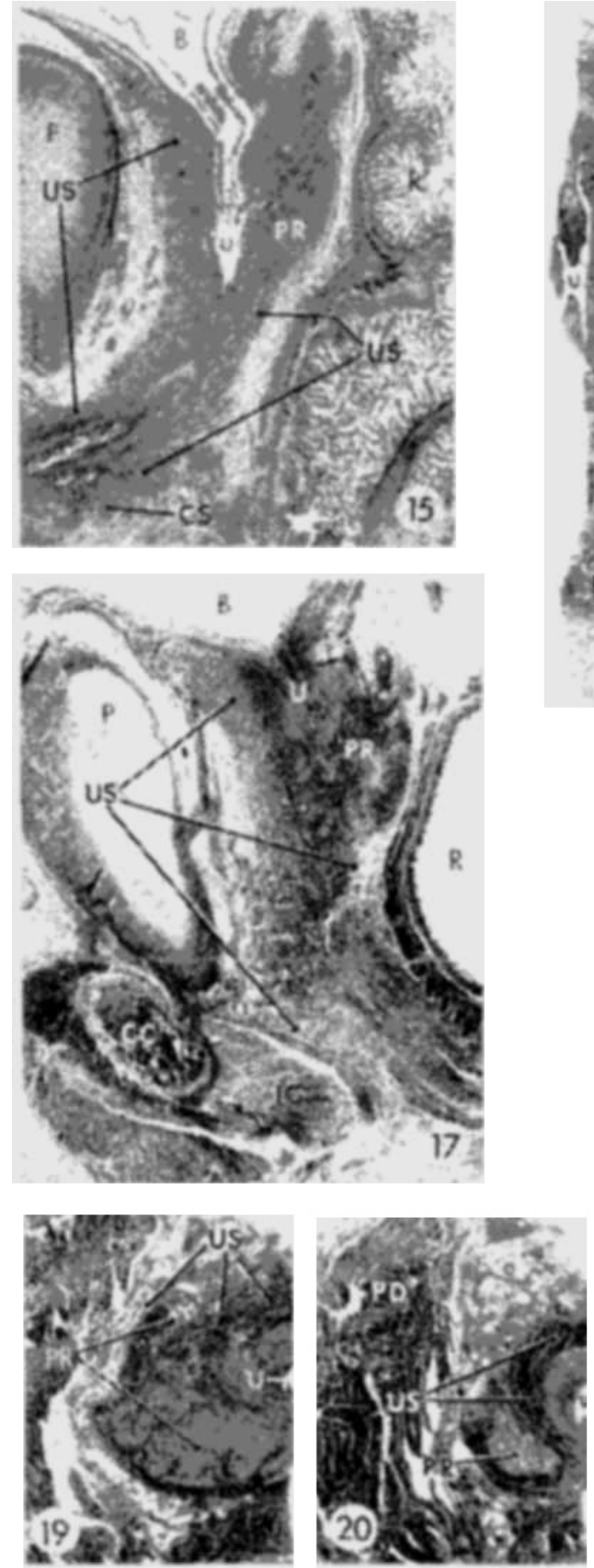
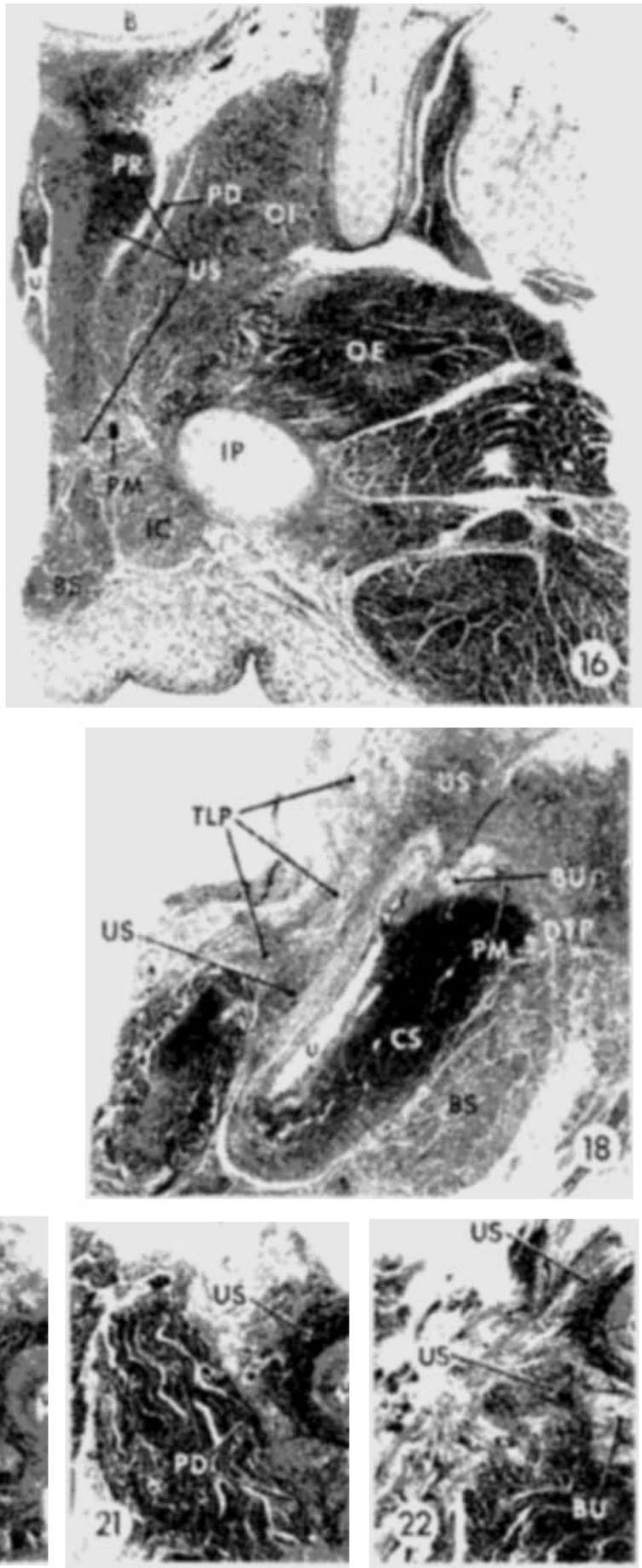
Fig. 23. Lateral view of prostate and pre-penile urethra in a male, 12 years. $\times 1.5$.

Fig. 24. Lateral view of prostate and pre-penile urethra in a male, 14 years. $\times 1.5$.

Fig. 25. Lateral view of bladder, seminal vesicle, ampulla of ductus deferens, and urethral sphincter muscle in a male, term. $\times 1.5$.

Fig. 26. Lateral view of bladder, urethra, prostate, urethral sphincter muscle removed in a male, term. $\times$ 1.5 .

Fig. 27. Lateral view of bladder and urethral sphincter muscle in a male, 4 years. $\times 2$.

Fig. 28. Perineal view of bladder, urethral sphincter demonstrating sphincter relation to urethra and deep transverse muscle of the perineum in a male, 4 years. $\times 2$.

Fig. 29. Lateral view of bladder, urethra, and prostate with urethral sphincter muscle removed in a male, 4 years. $\times 2$. 


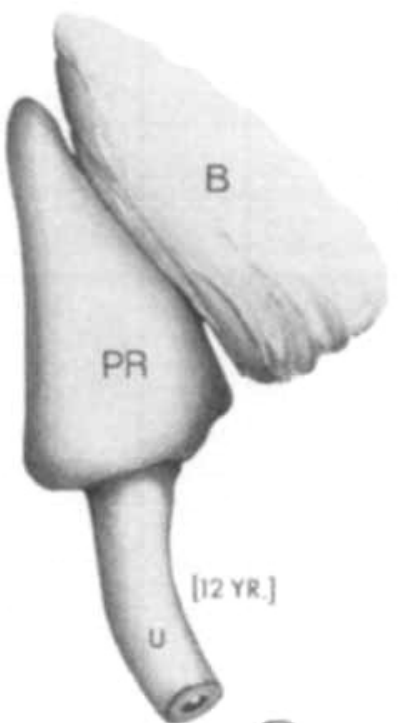

(23)

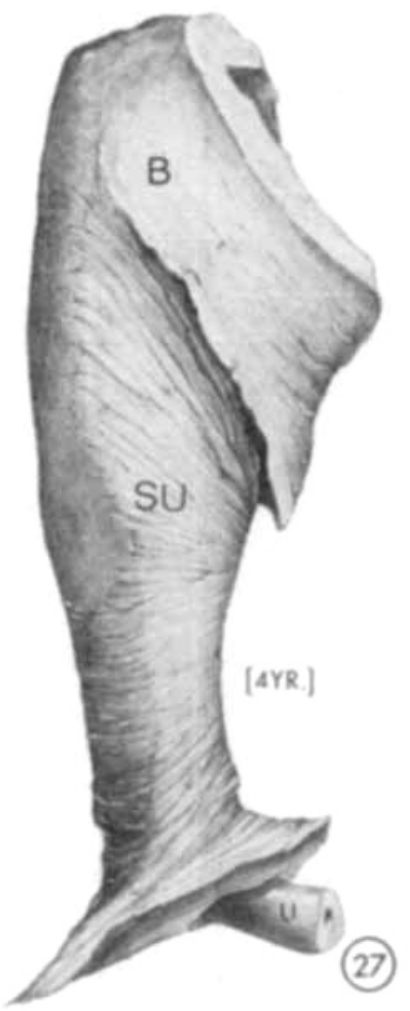

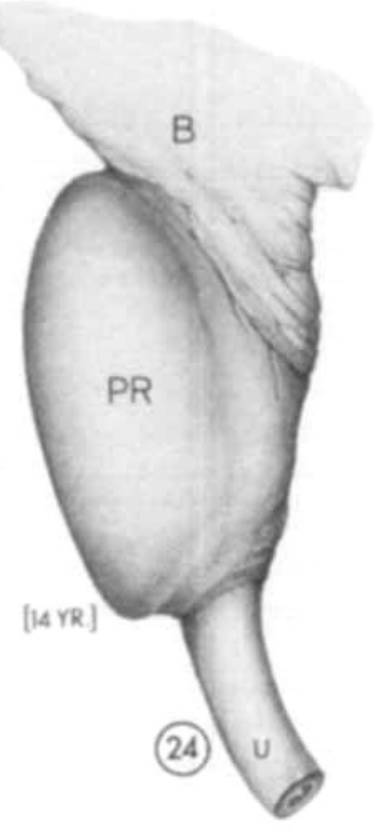
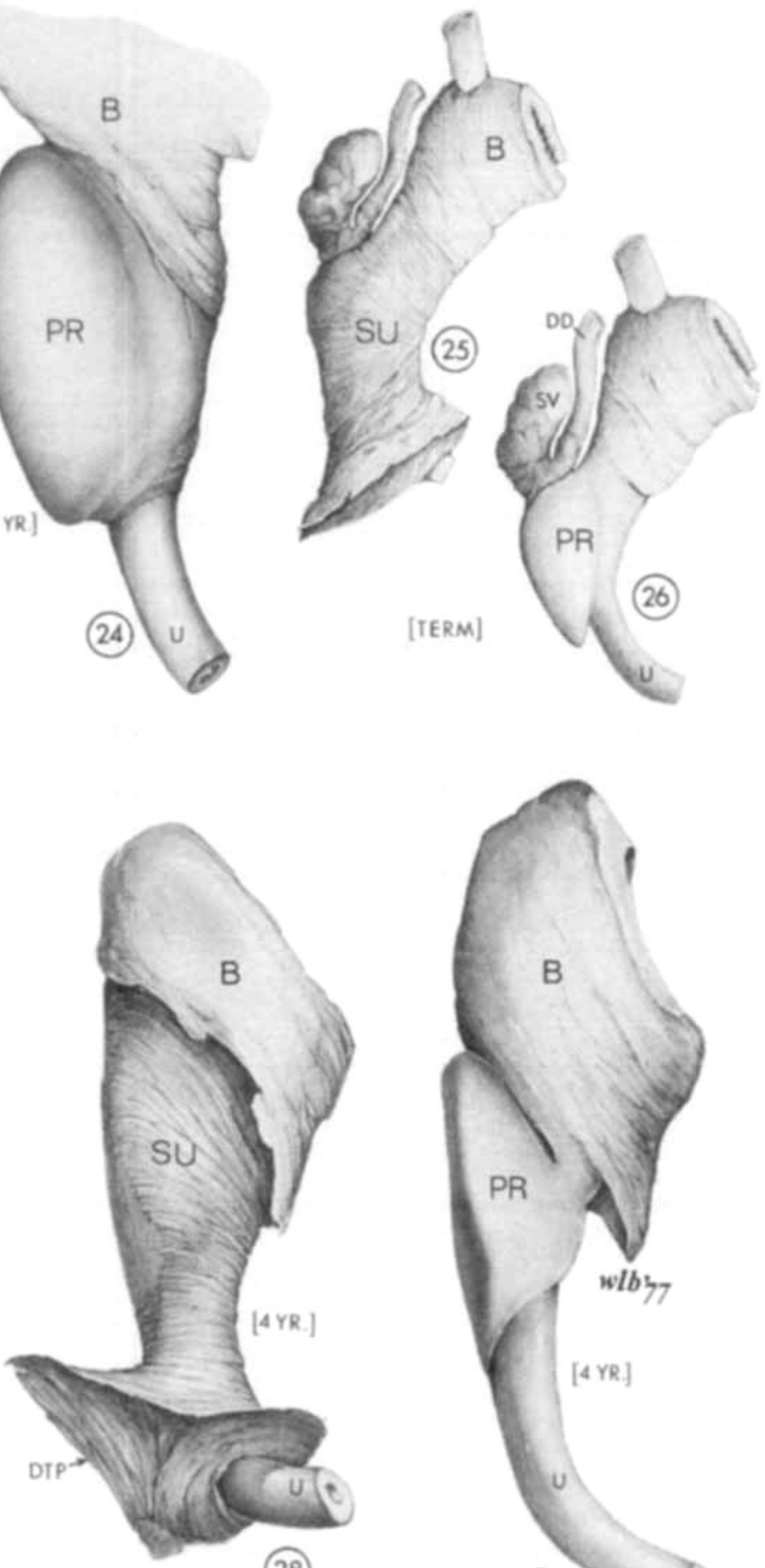

(28)

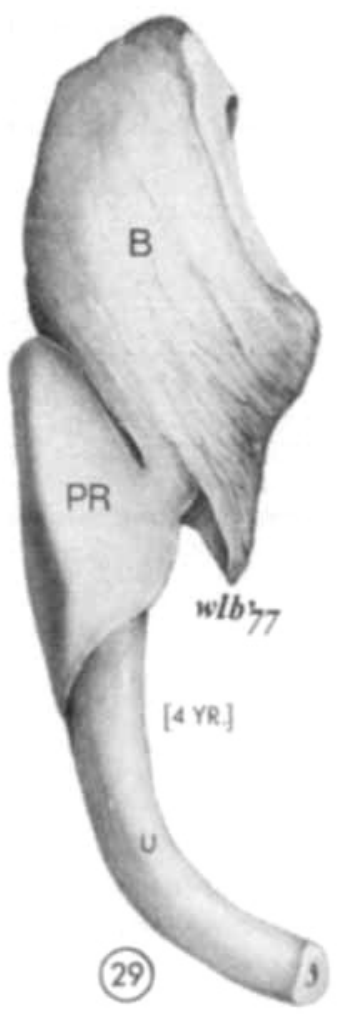


Fig. 30. Lateral view of bladder, prostate, and urethra with urethral sphincter muscle removed in a male, 25 years. $\times 2$.

Fig. 31. Oblique view of prostate and urethra with urethral sphincter muscle removed in a male, 25 years. $\times 2$.

Fig. 32. Lateral view of bladder, urethral sphincter muscle, and prostate in a male, 21 years, $\times 2$.

Fig. 33. Median section of bladder, urethra, prostate and urethral sphincter demonstrating extent of contact between urethra and the urethral sphincter muscle in a male, 21 years. $\times 2$. 

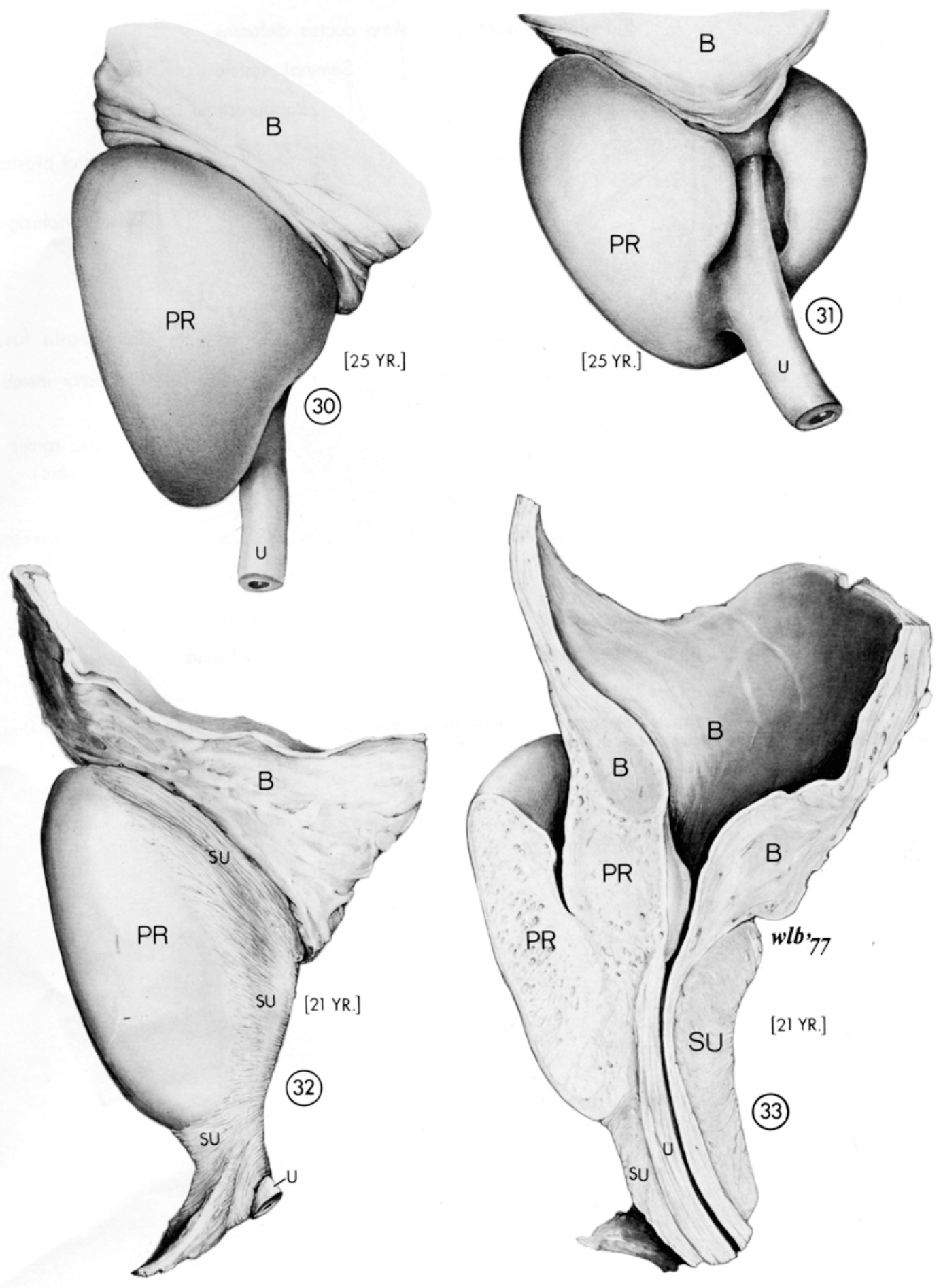


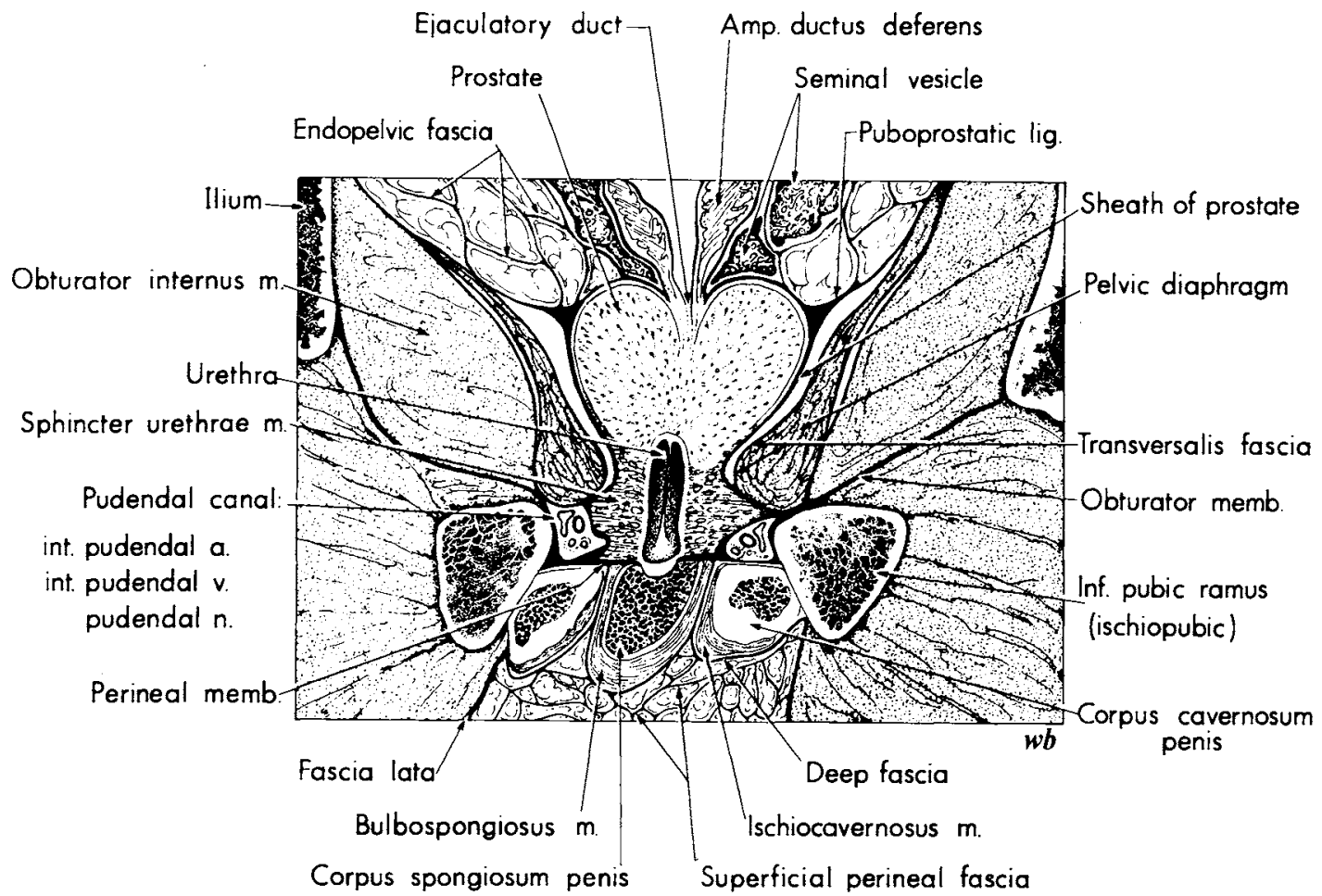

Fig. 34. Frontal section of male pelvis at right angles to perineal membrane, through the membranous urethra, demonstrating relations of fascial planes in the pelvis, urogenital hiatus, and perineum. Age 28. 